\title{
Effect of isothermal aging 2000 hours on intermetallics formed between Ni-Pd-Au with Sn-4Ag-0.5Cu solders
}

\begin{abstract}
The present study investigated the effect of isothermal aging up to 2000 hours on the intermetallics formed between $\mathrm{Sn}-4 \mathrm{Ag}-0.5 \mathrm{Cu}$ lead free solder on electroless nickel electroless palladium immersion gold surface finish (Ni-Pd-Au). For all parameters, aging have an effect of changing the intermetallic morphology to coarser and dense structure. The intermetallic compound formed for the interconnection of the lead free solder changes with increased aging time from $(\mathrm{Cu}, \mathrm{Ni}) 6 \mathrm{Sn} 5$ compound to $(\mathrm{Ni}, \mathrm{Cu}) 3 \mathrm{Sn} 4$. At the end of the 2000 hours aging time, it changes to Ni3Sn4. This is the effect of $\mathrm{Cu}$ element availability during the intermetallics growth process. Starting from as reflow process, (Pd, Ni)Sn4 intermetallics formed near the interface of the solder joint. The formation of the (Pd, Ni)Sn4 intermetallics act like a diffusion barrier to slow down the growth of interface intermetallics. Lastly, Au element was detected in the Pd-Sn based intermetallic after aging more than 1000 hours.
\end{abstract}

Keyword: Lead free solders; Isothermal aging; $\mathrm{Au} / \mathrm{Pd} / \mathrm{Ni}$; $\mathrm{Sn}-4 \mathrm{Ag}-0.5 \mathrm{Cu}$; Interfacial reaction 